\title{
Erratum to: Thermal microstructural changes of grain-supported limestones
}

\author{
Abdel Monem Mohamed Soltan • Wolf-Achim Kahl • \\ Mahmoud M. Hazem • Michael Wendschuh • \\ Reinhard X. Fischer
}

Published online: 22 June 2011

(C) Springer-Verlag 2011

Erratum to: Miner Petrol

DOI 10.1007/s00710-011-0151-0

Due to a processing error, the spelling of two authors' names were incorrect.

The correct names should read Wolf-Achim Kahl and Michael Wendschuh.

The online version of the original article can be found at http://dx.doi. org/10.1007/s00710-011-0151-0.

\footnotetext{
A. M. M. Soltan $(\bowtie)$

Geology Department, Faculty of Science, Ain Shams University,

Cairo 11566, Egypt

e-mail: abdelmonemsoltan@gmail.com

W.-A. Kahl

Geosciences Department, University of Bremen,

Bremen 28359, Germany

e-mail: wakahl@uni-bremen.de

M. M. Hazem

Chemistry Department, Faculty of Science, Ain Shams University,

Cairo 11566, Egypt

e-mail: drmahmoudhazem@gmail.com

M. Wendschuh $\cdot$ R. X. Fischer

Crystallography Department, Faculty of Science, Bremen

University,

Bremen 28359, Germany

M. Wendschuh

e-mail: mwendsc@uni-bremen.de

R. X. Fischer

e-mail: rfischer@uni-bremen.de
} 